\title{
Lymph node ratio as a predictor for outcome in oral squamous cell carcinoma: a multicenter population-based cohort study
}

\author{
Steffen Spoerl ${ }^{1} \cdot$ Michael Gerken $^{2} \cdot$ Andreas Mamilos $^{3} \cdot$ René Fischer $^{4} \cdot$ Stefanie Wolf $^{5} \cdot$ Felix Nieberle $^{6}$. \\ Christoph Klingelhöffer ${ }^{1} \cdot$ Johannes K. Meier ${ }^{1} \cdot$ Silvia Spoerl $^{7} \cdot$ Tobias Ettl $^{1} \cdot$ Torsten E. Reichert $^{1} \cdot$ Gerrit Spanier $^{1}$ (D)
}

Received: 29 November 2019 / Accepted: 24 July 2020 / Published online: 4 August 2020

(C) The Author(s) 2020

\begin{abstract}
Objectives Recently, multiple studies addressed the importance of lymph node ratio (LNR) in specifying patients' risk of disease recurrence in various malignancies. The present study examines the prognostic significance of LNR in predicting outcome of oral squamous cell carcinoma (OSCC) patients after surgical treatment with curative intent.

Methods Here, we describe a retrospective population-based cohort with 717 patients previously diagnosed with OSCC. Histopathologically verified lymph node metastasis was diagnosed in 290 patients. Among these patients, we evaluated the impact of LNR on overall survival (OAS) and recurrence-free survival (RFS) in uni- as well as multivariate analysis.

Results A median cutoff (0.055) in LNR was found to significantly predict outcome in OSCC patients. Five-year OAS was $54.1 \%$ in patients with a low LNR, whereas a high LNR was associated with a 5 -year OAS of $33.3 \%(p<0.001)$. Similar results were detected for RFS with a 5-year survival rate of $49.8 \%$ (LNR low) and 30.3\% (LNR high) $(p=0.002)$. Results were confirmed in multivariate Cox regression which substantiated the importance of LNR in predicting survival in OSCC patients. Conclusions LNR was shown to be an independent prognostic factor for outcome of OSCC in a population-based cohort in unias well as multivariate analysis. Hereby, a LNR $\geq 0.055$ predicted a shorter OAS and RFS in our cohort.

Clinical relevance Besides established histopathological factors, LNR can be used as a reliable predictor of outcome in OSCC and might therefore be further applied in evaluating adjuvant treatment after resection in curative intention.
\end{abstract}

Keywords Oral squamous cell carcinoma $\cdot$ Lymph node ratio $\cdot$ Lymph node density $\cdot$ Survival $\cdot$ Recurrence

Gerrit Spanier

gerrit.spanier@ukr.de

1 Department of Cranio-Maxillofacial Surgery, University Hospital Regensburg, D-93042 Regensburg, Germany

2 Tumor Center-Institute for Quality Management and Health Services Research, University of Regensburg, Regensburg, Germany

3 Institute of Pathology, University Regensburg, Regensburg, Germany

4 Department of Otorhinolaryngology, University Hospital Regensburg, Regensburg, Germany

5 Department of Otorhinolaryngology, St. Elisabeth Hospital Straubing, Straubing, Germany

6 Regensburg Center for Interventional Immunology, University Hospital Regensburg, Regensburg, Germany

7 Department of Internal Medicine 5-Hematology/Oncology, Friedrich-Alexander University Erlangen-Nürnberg, Erlangen, Germany

\section{Introduction}

Oral squamous cell carcinoma (OSCC) is one of the most common tumor entities worldwide.

With over 200,000 newly diagnosed cases, it accounts for nearly one-third of all head and neck cancers [1]. Therapeutic approaches are primarily based on combination of surgery, radiotherapy, and chemotherapy, depending on site and stage [2]. Apart from the HPV status, biomarkers to predict the outcome of OSCC patients, particularly in advanced stage disease, are still of utmost importance [3, 4]. Especially in patients with advanced disease, adjuvant treatment remains essential [5], including novel therapeutic approaches particularly in metastatic and recurrent disease: Immunotherapy thereby provides promising treatment options for OSCC patients and consecutively got implemented in routine patient care over the last years [6]. Only recently, the KEYNOTE048 phase 3 study focused on Pembrolizumab in HNSCC patients with metastatic or recurrent disease. Hereby, 
Pembrolizumab was characterized as an appropriate first-line therapy for patients with recurrent or metastatic HNSCC [7].

However, immunotherapeutic approaches are, from today's point of view, no adequate adjuvant treatment options in comparison with radiotherapy or radiochemotherapy. With these traditional adjuvant treatment modalities remaining essential, therapy-related adverse events should carefully taken into account. Relating thereto, the positive prognostic effect of adjuvant treatment needs to be further evaluated and confirmed for different individual subgroups of OSCC.

To determine cervical lymph node metastasis, the tumornode-metastasis (TNM) staging system contains several parameters including size, localization, and, to a certain extent, number of affected lymph nodes $[8,9]$. With up to $40 \%$ of OSCC patients presenting lymph node metastasis, a thoroughly performed neck dissection remains an essential aspect in treatment of OSCC [10]. However, the extent of each neck dissection is currently not taken into account when using the TNM classification system, which is still crucial for therapy evaluation and planning treatment strategies [11]. However, alternative staging systems were recently taken into account when predicting outcome in OSCC, especially regarding lymph node ratio (LNR) or the number of positive lymph nodes as potential prognostic factors [12-14].

LNR combines information of dissected nodes as well as the number of positive lymph nodes after histopathological examination. It is defined by the ratio of positive lymph nodes and the entire number of dissected lymph nodes. In various tumor entities, LNR was shown as a valuable prognostic parameter by potently predicting patients' outcome [15-17].

Even though single center studies already revealed the impact of LNR as a prognostic factor in predicting outcome of OSCC patients after resection with curative intent [12, 18, 19], we conducted a multicenter cohort study with a populationbased approach in Eastern Bavaria to further evaluate the prognostic impact of LNR in OSCC.

\section{Materials and methods}

\section{Patient selection}

A multicenter retrospective cohort study was conducted utilizing the database of the Tumor Center Regensburg for the region of Eastern Bavaria. This region of Germany, including the districts of Upper Palatinate and Lower Bavaria, represents a population of around 2.3 million people. The study involved only adult individuals residing in the aforementioned region. All patients had been examined and treated for a newly diagnosed OSCC between 2004 and 2017. Diagnostic workup and consecutive treatment were evaluated at three different medical centers: the Department of Cranio-Maxillofacial Surgery as well as the Department of Otorhinolaryngology, both at the
University Hospital Regensburg, and the Department of Otorhinolaryngology at the St. Elisabeth Hospital Straubing.

Patients with previous neck dissection or primary radio(chemo)therapy of head and neck squamous cell carcinoma were excluded. A total of 717 patients were included in the study. These patients did not undergo neoadjuvant treatment and underwent surgical resection of the primary lesion to negative margins. The mean resection margin was $5 \mathrm{~mm}$ for patients with detailed information from the histopathological report. Additionally, every patient received a neck dissection with a varying extent of included cervical levels, based on the primary tumor site and preoperative radiological findings. Staging was performed according to the UICC guidelines in the 7th edition [20]. Patient data was retrieved from medical records, including age, gender, positive smoking and alcohol anamnesis, tumor site, tumor-node-metastasis (TNM) stage, grading, and surgical and adjuvant therapy. Age-adjusted Charlson comorbidity index (ACCI) was calculated as previously described and without taking OSCC into account [21].

Adjuvant treatment was based on the recommendation of the multidisciplinary tumor board, and radiotherapy or radiochemotherapy was used accordingly. Hereby, frequent indications for adjuvant treatment were given by higher pT-stages, perinodal invasion, or a $\mathrm{pN}+$ status. However, some patients were not eligible for an adjuvant radiochemotherapeutical approach due to impaired medical conditions. Thence, a sole adjuvant radiotherapy was applied. Some patients refused to adjuvant treatment anyway.

Disease relapse was defined as locoregional disease recurrence or distant metastasis by radiologic evidence with clinical correlation or histopathological confirmation by biopsy. Data concerning recurrence-free survival (RFS) and overall survival (OAS) were obtained from medical records, death certificates, registration offices, and the Clinical Cancer Registry of the Tumor Center-Institute for Quality Management and Health Services Research, University of Regensburg, Germany. According to the approval of this study by the institutional ethics committee, patient data was collected completely anonymized. The end of observation was defined as June 30, 2019. Median follow-up time for the entire cohort was 89 months.

\section{Statistics}

LNR was defined by the ratio of positive lymph nodes and the entire number of dissected lymph nodes and was used as a categorized variable. For outcome analysis, median and quartiles were used as cutoff values for categorizing LNR. Metric variables were analyzed for differences in their means using student's $t$ test in case of normal distribution, otherwise using Mann-Whitney $U$ test. Independence of categorical variables was analyzed using Pearson's chi-square test. Overall and recurrence-free survival time was calculated from date of 
resection to date of death, date of first recurrence, or date last alive until the end point. Survival analyses were performed using the Kaplan-Meier and Cox regression methods. Differences in outcome estimates were tested using the logrank test. For risk adjustment, multivariate Cox regression was applied, adjusting for demographical, clinical, and histopathological variables, $\mathrm{pT}-$ and $\mathrm{pN}$-status, grading, age, gender, and alcohol and nicotine abuse. Results were reported with hazard ratios (HRs) and 95\% confidence intervals (CIs). A $p$ value $<0.05$ was considered significant for all tests. All analyses were performed using IBM SPSS Statistics Version 25.0 (IBM Corp., Armonk, N.Y., USA).

\section{Results}

In total, 717 OSCC patients were included in this retrospective analysis, and the clinicopathological features are summarized in Table 1. Of patients, $71.8 \%$ were male, and mean age was 60.8 years (median 60.1, range 28-91 years). Most patients had a positive history of nicotine $(75.0 \%)$ and alcohol abuse $(68.6 \%)$, and most tumors were located at the floor of the mouth and tongue (68.4\%).

In 290 patients (40.4\%), lymph node metastasis was diagnosed after tumor resection, and most tumors were staged UICC class IV (37.1\%). Of patients, $46.8 \%$ received adjuvant therapy, with only 103 patients $(14.4 \%)$ receiving adjuvant radiochemotherapy (Table 1 ).

In patients with histopathological verification of lymph node metastasis $(n=290)$, neck dissection resulted in a median lymph node yield of 38.0 (range: 1-104). The median of positive lymph nodes was 2 (range: $1-41$ ), resulting in a median LNR of 0.055 (range: 0.011-1.00) (Table 2). Differences in clinicopathological characteristics in patients with positive lymph nodes according to bivariate LNR distribution were evaluated: Here, significant differences were seen for ACCI $(p=0.048)$, extent of neck dissection $(p=0.002), \mathrm{pT}$ - and $\mathrm{pN}$ stage $(p=0.004, p<0.001)$, UICC stage $(p<0.001)$ as well as histopathological verification of extranodal spread $(p<0.001)$ (Table 3).

Kaplan-Meier survival analysis in patients with lymph node metastasis revealed a 5 -year OAS of $54.1 \%$ for LNR $\leq 0.055$. In contrast, a LNR $>0.055$ resulted in a 5 -year OAS of $33.3 \%$ in our retrospective cohort $(p=0.001)$. For RFS in patients with lymph node metastasis, survival analysis displayed a 5-year RFS, using a median cutoff in LNR, of $49.8 \%$ for a LNR $\leq 0.055$. A LNR $>0.055$ resulted in a 5 -year RFS of $30.3 \%(p=0.002)$. KaplanMeier curves are shown in Fig. $1 \mathrm{a}$ and b. Results of impaired survival in case of a LNR $>0.055$ were substantiated by multivariate Cox regression. Hereby, a LNR > 0.055 resulted in a significantly restricted OAS $(\mathrm{HR}=$ 1.492 ; $95 \%$ CI $1.026-2.168, p=0.036)$ and RFS (HR =
1.503 ; 95\% CI $1.049-2.155, p=0.027$ ) in our retrospective cohort (tables not shown).

Additionally, we not only differentiated LNR by a median cutoff. For further survival analysis, a categorization according to quartiles was applied ( $\mathrm{LNR}<0.03, \mathrm{LNR}=0.03-0.055$, $\mathrm{LNR}=0.055-0.107, \mathrm{LNR}>0.107)$. Survival analysis revealed differences in 5-year OAS for the lowest 25\% (53.5\% 5 -year OAS), the $25-50 \%(52.7 \%)$, the $50-75 \%$ (39.7\%), and the highest $75 \%(25.1 \%)$ in LNR distribution.

Similar results were seen for 5-year RFS for the lowest $25 \%$ (49.2\% 5-year RFS), the 25-50\% (48.6\%), the 50-75\% (35.2\%), and the highest $75 \%$ (23.8\%) (Fig. $2 \mathrm{a}$ and b).

Beyond univariate survival analysis, we performed multivariate Cox regression analysis for quartiles in LNR distribution with risk adjustment for $\mathrm{pT}$ - as well as $\mathrm{pN}$-status, grading, age, gender, alcohol as well as nicotine abuse, adjuvant therapy, and extranodal spread. Table 4 shows results of uni- as well as multivariate Cox regression for OAS depending on LNR classified in quartiles in the subcohort of patients with lymph node metastasis. Hereby, univariate Cox regression displayed significant differences in OAS for $\mathrm{pT}$ - and $\mathrm{pN}$-stage, age and extranodal spread with significantly impaired (decreased) survival times for more advanced $\mathrm{pT}$-stages (pT3: $p=0.021$, pT4: $p=0.009)$, a pN3-status $(p=0.001)$, advanced patients age $(p=0.039)$, and histopathological verification of extranodal spread $(p<0.001)$. After risk adjustment by multivariate Cox regression, a high pTN-stage could not be linked to a shorter OAS unlike results of univariate analysis. However, an elevated LNR (LNR > 0.107) hereby clearly impaired OAS of patients with lymph node metastasis when compared with a lower ratio $(\mathrm{HR}=1.921 ; 95 \% \mathrm{CI}$ $1.080-3.419, p=0.026$ ) (Table 4). Both univariate and multivariate analyses show a clear trend of HRs towards a lower OAS with increasing LNR (Table 4).

\section{Discussion}

For patients diagnosed with OSCC, receiving surgical resection of the primary tumor, negative margins and a cervical lymph node dissection represent state-of-the-art therapy [2]. However, lymph node metastasis has been reported as one of the most important prognostic factors in OSCC [22]. Therefore, the $\mathrm{pN}$-status is an essential aspect of current staging systems [8], differentiating between numbers of affected lymph nodes, dimension of lymph node metastasis, and site of occurrence [9]. Unfortunately, the $\mathrm{pN}$-status has several limitations due to different surgical techniques and discrepancies in the extent of neck dissection and histopathological examination of dissected nodes. Various authors therefore postulate that a neck dissection should entail a defined number of dissected lymph nodes. While the 8th edition of the American Joint Committee on Cancer (AJCC) staging manual regards a 
Table 1 Clinicopathological characteristics in complete cohort $(n=717)$, UICC 7th edition

\begin{tabular}{|c|c|c|c|}
\hline & & $N$ & $\%$ \\
\hline \multirow[t]{2}{*}{ Sex } & Female & 202 & 28.2 \\
\hline & Male & 515 & 71.8 \\
\hline \multirow[t]{5}{*}{ Age at diagnosis } & $<50$ & 103 & 14.4 \\
\hline & $50.0-59.9$ & 253 & 35.3 \\
\hline & $60.0-69.9$ & 217 & 30.3 \\
\hline & $70.0-79.9$ & 114 & 15.9 \\
\hline & $>80$ & 30 & 4.2 \\
\hline \multirow[t]{2}{*}{ Smoking } & No & 179 & 25.0 \\
\hline & Yes & 538 & 75.0 \\
\hline \multirow[t]{2}{*}{ Alcohol } & No & 225 & 31.4 \\
\hline & Yes & 492 & 68.6 \\
\hline \multirow[t]{7}{*}{ Age-adjusted Charlson comorbidity index } & 0 & 74 & 10.3 \\
\hline & 1 & 148 & 20.6 \\
\hline & 2 & 155 & 21.6 \\
\hline & 3 & 116 & 16.2 \\
\hline & 4 & 83 & 11.6 \\
\hline & 5 & 59 & 8.2 \\
\hline & $6+$ & 82 & 11.4 \\
\hline \multirow[t]{6}{*}{ Anatomical site } & Buccal mucosa & 51 & 7.1 \\
\hline & Upper alveolus and gingiva & 22 & 3.1 \\
\hline & Lower alveolus and gingiva & 106 & 14.8 \\
\hline & Hard palate & 48 & 6.7 \\
\hline & Tongue & 210 & 29.3 \\
\hline & Floor of mouth & 280 & 39.1 \\
\hline \multirow[t]{4}{*}{ Tumor size } & $\mathrm{T} 1$ & 290 & 40.4 \\
\hline & $\mathrm{T} 2$ & 236 & 32.9 \\
\hline & $\mathrm{T} 3$ & 56 & 7.8 \\
\hline & $\mathrm{T} 4$ & 135 & 18.8 \\
\hline \multirow[t]{6}{*}{ Cervical lymph node metastasis } & No & 427 & 59.5 \\
\hline & N1 & 110 & 15.3 \\
\hline & $\mathrm{N} 2 \mathrm{a}$ & 8 & 1.1 \\
\hline & $\mathrm{N} 2 \mathrm{~b}$ & 113 & 15.8 \\
\hline & $\mathrm{N} 2 \mathrm{c}$ & 50 & 7.0 \\
\hline & N3 & 9 & 1.3 \\
\hline \multirow[t]{3}{*}{ Grading } & G1 & 51 & 7.1 \\
\hline & G2 & 528 & 73.6 \\
\hline & $\mathrm{G} 3 / 4$ & 138 & 19.2 \\
\hline \multirow[t]{4}{*}{ UICC stage } & I & 219 & 30.5 \\
\hline & II & 117 & 16.3 \\
\hline & III & 115 & 16.0 \\
\hline & IV & 266 & 37.1 \\
\hline \multirow{3}{*}{ Adjuvant therapy } & No & 382 & 53.3 \\
\hline & Radiotherapy & 232 & 32.4 \\
\hline & Radiochemotherapy & 103 & 14.4 \\
\hline \multirow[t]{2}{*}{ Death } & Alive & 395 & 55.1 \\
\hline & Dead & 322 & 44.9 \\
\hline \multirow[t]{3}{*}{ Death or recurrence } & Alive without recurrence & 353 & 49.2 \\
\hline & Death or recurrence & 364 & 50.8 \\
\hline & Total & 717 & 100.0 \\
\hline
\end{tabular}

Table 2 Characteristics of dissected lymph nodes in patients with cervical lymph node metastasis $(n=290)$

\begin{tabular}{lccccc}
\hline & Mean & Median & SD & Minimum & Maximum \\
\hline Lymph node yield & 39.6 & 38.0 & 19.2 & 1 & 104 \\
Number of positive lymph nodes & 3.1 & 2.0 & 4.8 & 1 & 41 \\
Lymph node ratio & 0.09044 & 0.05481 & 0.11061 & 0.01111 & 1.00000 \\
\hline
\end{tabular}


Table 3 Patients clinicopathological characteristics according to lymph node ratio $(n=290)$

\begin{tabular}{|c|c|c|c|c|c|c|c|c|}
\hline & & Lym & hode rati & & & & & \\
\hline & & Low & & High & & Total & & $\chi^{2}$ \\
\hline & & $N$ & $\%$ & $N$ & $\%$ & $N$ & $\%$ & $\rho$ \\
\hline Sex & Female & 37 & 12.8 & 39 & 13.4 & 76 & 26.2 & 0.789 \\
\hline & Male & 108 & 37.2 & 106 & 36.6 & 214 & 73.8 & \\
\hline Age at diagnosis & $<50$ & 28 & 19.3 & 21 & 14.5 & 49 & 16.9 & 0.325 \\
\hline & $50.0-59.9$ & 52 & 35.9 & 48 & 33.1 & 100 & 34.5 & \\
\hline & $60.0-69.9$ & 39 & 26.9 & 39 & 26.9 & 78 & 26.9 & \\
\hline & $70.0-79.9$ & 23 & 15.9 & 28 & 19.3 & 51 & 17.6 & \\
\hline & $>80$ & 3 & 2.1 & 9 & 6.2 & 12 & 4.1 & \\
\hline Smoking anamnesis & No & 29 & 10.0 & 33 & 11.4 & 62 & 21.4 & 0.567 \\
\hline & Yes & 116 & 40.0 & 112 & 38.6 & 228 & 78.6 & \\
\hline Alcohol anamnesis & No & 36 & 12.4 & 44 & 15.2 & 80 & 27.6 & 0.293 \\
\hline & Yes & 109 & 37.6 & 101 & 34.8 & 210 & 72.4 & \\
\hline Age-adjusted Charlson comorbidity index & 0 & 20 & 6.9 & 12 & 4.1 & 32 & 11.0 & 0.048 \\
\hline & 1 & 36 & 12.4 & 24 & 8.3 & 60 & 20.7 & \\
\hline & 2 & 29 & 10.0 & 27 & 9.3 & 56 & 19.3 & \\
\hline & 3 & 24 & 8.3 & 29 & 10.0 & 53 & 18.3 & \\
\hline & 4 & 16 & 5.5 & 13 & 4.5 & 29 & 10.0 & \\
\hline & 5 & 10 & 3.4 & 15 & 5.2 & 25 & 8.6 & \\
\hline & $6+$ & 10 & 3.4 & 25 & 8.6 & 35 & 12.1 & \\
\hline Anatomical site & Buccal mucosa & 5 & 1.7 & 16 & 5.5 & 21 & 7.2 & 0.069 \\
\hline & Upper alveolus and gingiva & 5 & 1.7 & 5 & 1.7 & 10 & 3.4 & \\
\hline & Lower alveolus and gingiva & 21 & 7.2 & 16 & 5.5 & 37 & 12.8 & \\
\hline & Hard palate & 10 & 3.4 & 14 & 4.8 & 24 & 8.3 & \\
\hline & Tongue & 39 & 13.4 & 46 & 15.9 & 85 & 29.3 & \\
\hline & Floor of mouth & 65 & 22.4 & 48 & 16.6 & 113 & 39.0 & \\
\hline Neck dissection side & Left & 10 & 3.4 & 25 & 8.6 & 35 & 12.1 & 0.002 \\
\hline & Right & 13 & 4.5 & 24 & 8.3 & 37 & 12.8 & \\
\hline & Bilateral & 122 & 42.1 & 96 & 33.1 & 218 & 75.2 & \\
\hline Tumor size & $\mathrm{T} 1$ & 45 & 15.5 & 25 & 8.6 & 70 & 24.1 & 0.004 \\
\hline & $\mathrm{T} 2$ & 61 & 21.0 & 58 & 20.0 & 119 & 41.0 & \\
\hline & $\mathrm{T} 3$ & 10 & 3.4 & 25 & 8.6 & 35 & 12.1 & \\
\hline & $\mathrm{T} 4$ & 29 & 10.0 & 37 & 12.8 & 66 & 22.8 & \\
\hline Cervical lymph node & N1 & 93 & 64.1 & 17 & 11.7 & 110 & 37.9 & $<0.001$ \\
\hline metastasis & $\mathrm{N} 2 \mathrm{a}$ & 6 & 4.1 & 2 & 1.4 & 8 & 2.8 & \\
\hline & $\mathrm{N} 2 \mathrm{~b}$ & 33 & 22.8 & 80 & 55.2 & 113 & 39.0 & \\
\hline & $\mathrm{N} 2 \mathrm{c}$ & 11 & 7.6 & 39 & 26.9 & 50 & 17.2 & \\
\hline & $\mathrm{N} 3$ & 2 & 1.4 & 7 & 4.8 & 9 & 3.1 & \\
\hline Grading & G1 & 5 & 1.7 & 2 & 0.7 & 7 & 2.4 & 0.184 \\
\hline & G2 & 112 & 38.6 & 104 & 35.9 & 216 & 74.5 & \\
\hline & $\mathrm{G} 3 / 4$ & 28 & 9.7 & 39 & 13.4 & 67 & 23.1 & \\
\hline UICC stage & I & 0 & 0.0 & 1 & 0.3 & 1 & 0.3 & $<0.001$ \\
\hline & II & 0 & 0.0 & 0 & 0.0 & 0 & 0.0 & \\
\hline & III & 78 & 26.9 & 16 & 5.5 & 94 & 32.4 & \\
\hline & IV & 67 & 23.1 & 128 & 44.1 & 195 & 67.2 & \\
\hline Adjuvant therapy & No & 36 & 12.4 & 27 & 9.3 & 63 & 21.7 & 0.326 \\
\hline & Radiotherapy & 71 & 24.5 & 71 & 24.5 & 142 & 49.0 & \\
\hline & Radiochemotherapy & 38 & 13.1 & 47 & 16.2 & 85 & 29.3 & \\
\hline Extranodal spread & No & 123 & 84.8 & 89 & 61.4 & 212 & 73.1 & $<0.001$ \\
\hline & Yes & 22 & 15.2 & 56 & 38.6 & 78 & 26.9 & \\
\hline
\end{tabular}


Table 3 (continued)

\begin{tabular}{|c|c|c|c|c|c|c|c|c|}
\hline & & \multicolumn{6}{|c|}{ Lymph node ratio } & \multirow{3}{*}{$\begin{array}{l}\chi^{2} \\
\rho\end{array}$} \\
\hline & & \multicolumn{2}{|l|}{ Low } & \multicolumn{2}{|c|}{ High } & \multicolumn{2}{|c|}{ Total } & \\
\hline & & $N$ & $\%$ & $N$ & $\%$ & $N$ & $\%$ & \\
\hline & Total & 145 & 100.0 & 145 & 100.0 & 290 & 100.0 & \\
\hline Death & $\begin{array}{l}\text { Alive } \\
\text { Dead }\end{array}$ & $\begin{array}{l}67 \\
78\end{array}$ & $\begin{array}{l}23.1 \\
26.9\end{array}$ & $\begin{array}{l}49 \\
96\end{array}$ & $\begin{array}{l}16.9 \\
33.1\end{array}$ & $\begin{array}{l}116 \\
174\end{array}$ & $\begin{array}{l}40.0 \\
60.0\end{array}$ & 0.031 \\
\hline Death or recurrence & $\begin{array}{l}\text { Alive without recurrence } \\
\text { Death or recurrence }\end{array}$ & $\begin{array}{l}62 \\
83\end{array}$ & $\begin{array}{l}21.4 \\
28.6\end{array}$ & $\begin{array}{r}42 \\
103\end{array}$ & $\begin{array}{l}14.5 \\
35.5\end{array}$ & $\begin{array}{l}104 \\
186\end{array}$ & $\begin{array}{l}35.9 \\
64.1\end{array}$ & 0.014 \\
\hline & Total & 145 & 50.0 & 145 & 50.0 & 290 & 100.0 & \\
\hline
\end{tabular}

Definition for low (LNR $\leq$ median) and high (LNR > median), UICC 7th edition

lymph node yield of at least 15 nodes as an adequate extent for a neck dissection [23], some authors recommend a nodal yield of at least 18 lymph nodes in an elective neck dissection to obtain a beneficial prognosis for OSCC patients [24].

In our retrospective cohort including 717 patients with primarily resected OSCC, lymph node metastasis occurred in 290 patients $(40.4 \%)$. Hereby, neck dissection resulted in a median lymph node yield of 38 lymph nodes, which certainly represents, in comparison with previously published results [12], an adequate number.

Nevertheless, the number of histopathologically positive lymph nodes among the total amount of dissected nodes was already proposed as a predictive marker for outcome in head and neck cancer in 1994 [25]. Recently, numerous authors characterized the number of positive lymph nodes as an independent prognostic factor for OSCC $[13,26]$. Even though the occurrence of positive lymph nodes is taken into account in the current TNM classification for OSCC [9], no further differentiation is made if more than one lymph node is affected.

In this regard, an alternative lymph node staging system is of utmost importance. LNR might ensure both information: the number of lymph nodes being dissected and those being positive for lymph node metastasis. The beneficial aspect of LNR takes the differential extent of each individual neck dissection into account. It results in a simple ratio which can be calculated based on each individual lymph node number. Hereby, a less extensive neck dissection is reported to entail a higher LNR, which might impair patients' outcome [18].

Over the last years, numerous authors examined the potential prognostic value of LNR on various subsites of head and neck cancer $[27,28]$. To date, there is presently growing evidence in OSCC that LNR might outmatch conventional nodal staging systems $[3,18,29]$. In this regard, our univariate survival analysis shows that a $\mathrm{pN} 3$-status was significantly correlated with decreased OAS in a retrospective cohort analysis. However, this effect is not entirely confirmed in multivariate analysis (Table 4). For LNR, uni- as well as multivariate analysis revealed a significant correlation of higher LNRs with impaired patients' survival in OSCC (Table 4). In multivariate analysis, LNR might therefore surpass the conventional $\mathrm{pN}$ classification.

In the present study, we investigate LNR as a potential predictor of survival in OSCC patients with lymph node metastasis. A cutoff in LNR was either used as the median
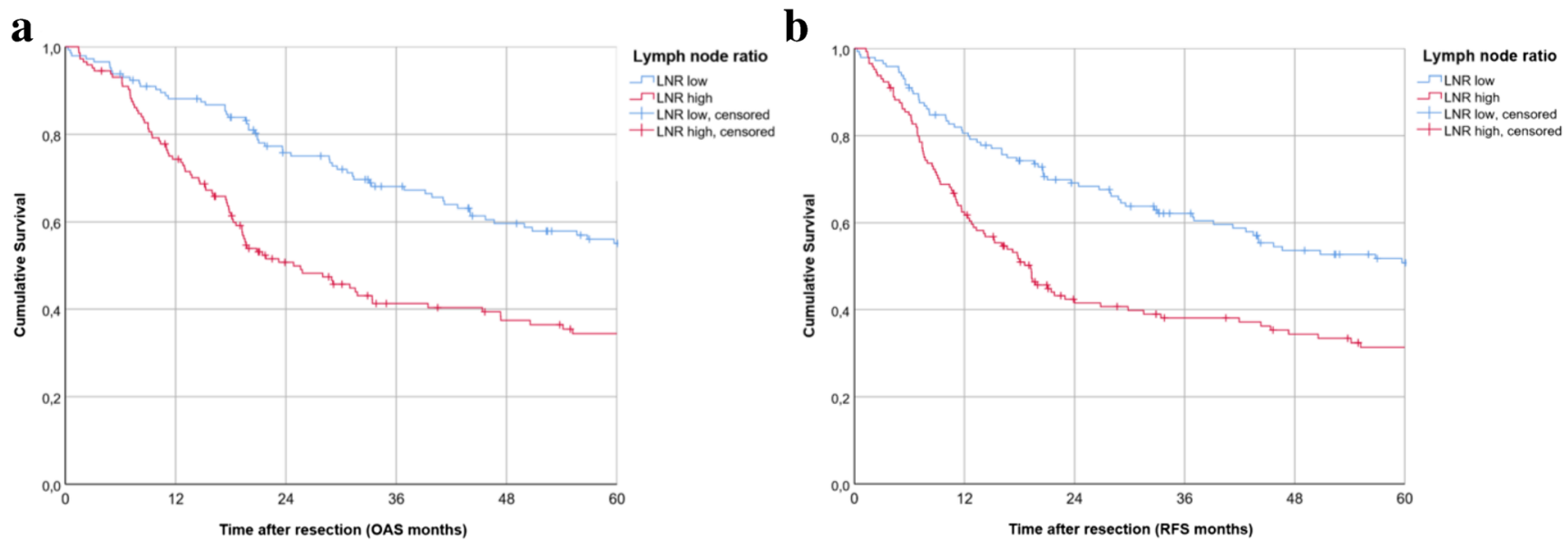

Fig. 1 Survival in OSCC patients: Kaplan-Meier curves for OAS $(p=0.001)(\mathbf{a})$ and RFS $(p=0.002)(\mathbf{b})$ for LNR low $(\leq 0.055)$ and high $(>0.055)$ 
a

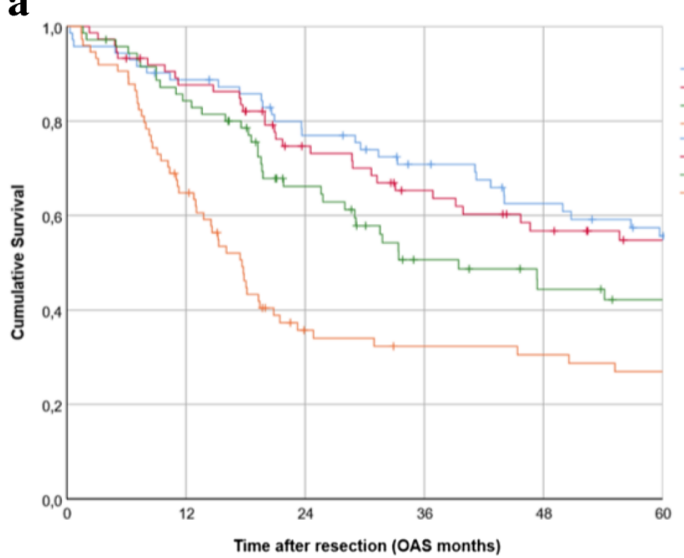

b

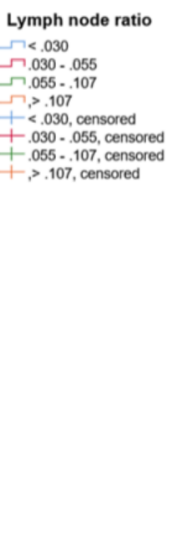

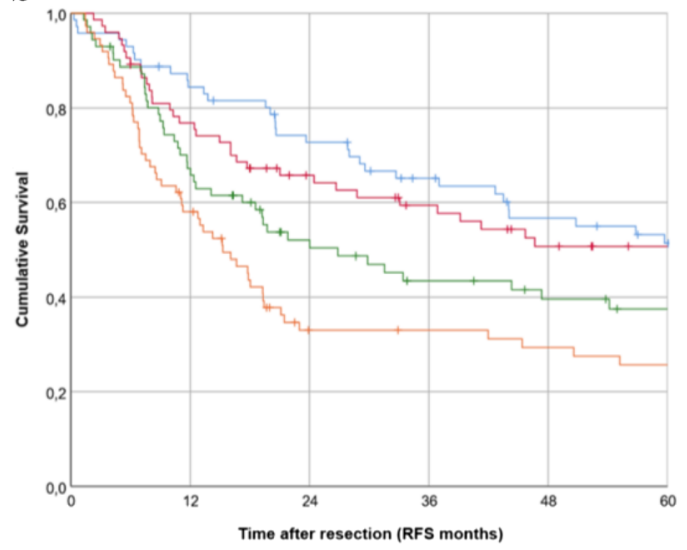

Lymph node ratio

$\rightarrow>030$

$\neg .030 \cdot .055$ $.055 \cdot .107$
$>>107$ - $<.030$, censored $+.030-.055$, censored $\rightarrow .107$. censersod

Fig. 2 Survival in OSCC patients: Kaplan-Meier curves for OAS (a) and RFS (b) for LNR with quartile cutoff points

Table 4 Uni- and multivariate Cox regression for LNR and prognostic factors on OAS $(n=290)$, UICC 7th edition

\begin{tabular}{|c|c|c|c|c|c|c|c|c|c|}
\hline \multirow[t]{2}{*}{ Variable } & \multirow[t]{2}{*}{ Category } & \multicolumn{4}{|c|}{ Univariate Cox regression } & \multicolumn{4}{|c|}{ Multivariate Cox regression } \\
\hline & & $\rho$ & HR & $\begin{array}{l}\text { Lower } \\
95 \% \text { CI }\end{array}$ & $\begin{array}{l}\text { Upper } \\
95 \% \text { CI }\end{array}$ & $\rho$ & HR & $\begin{array}{l}\text { Lower } \\
95 \% \text { CI }\end{array}$ & $\begin{array}{l}\text { Upper } \\
95 \% \text { CI }\end{array}$ \\
\hline \multirow[t]{4}{*}{ LNR (quartiles) } & $<0.030$ & & 1.000 & & & & 1.000 & & \\
\hline & $0.030-0.055$ & 0.854 & 1.043 & 0.667 & 1.631 & 0.752 & 1.088 & 0.645 & 1.837 \\
\hline & $0.055-0.107$ & 0.274 & 1.280 & 0.822 & 1.991 & 0.658 & 1.140 & 0.638 & 2.035 \\
\hline & $>0.107$ & $<0.001$ & 2.137 & 1.413 & 3.231 & 0.026 & 1.921 & 1.080 & 3.419 \\
\hline \multirow[t]{4}{*}{ Tumor size } & $\mathrm{T} 1$ & & 1.000 & & & & 1.000 & & \\
\hline & $\mathrm{T} 2$ & 0.069 & 1.461 & 0.971 & 2.198 & 0.239 & 1.292 & 0.843 & 1.979 \\
\hline & $\mathrm{T} 3$ & 0.021 & 1.870 & 1.100 & 3.180 & 0.247 & 1.428 & 0.781 & 2.611 \\
\hline & $\mathrm{T} 4$ & 0.009 & 1.820 & 1.161 & 2.851 & 0.019 & 1.784 & 1.102 & 2.889 \\
\hline \multirow[t]{3}{*}{ Cervical lymph node metastasis } & $\mathrm{N} 1$ & & 1.000 & & & & 1.000 & & \\
\hline & $\mathrm{N} 2$ & 0.145 & 1.266 & 0.922 & 1.738 & 0.700 & 0.908 & 0.556 & 1.483 \\
\hline & N3 & 0.001 & 3.851 & 1.730 & 8.575 & 0.645 & 1.275 & 0.453 & 3.587 \\
\hline \multirow[t]{2}{*}{ Grading } & $\mathrm{G} 1 / 2$ & & 1.000 & & & & 1.000 & & \\
\hline & $\mathrm{G} 3 / 4$ & 0.214 & 1.247 & 0.880 & 1.767 & 0.406 & 1.167 & 0.810 & 1.681 \\
\hline \multirow[t]{5}{*}{ Age at diagnose } & $<50$ & & 1.000 & & & & 1.000 & & \\
\hline & $50.0-59.9$ & 0.383 & 0.814 & 0.512 & 1.293 & 0.151 & 0.699 & 0.429 & 1.139 \\
\hline & $60.0-69.9$ & 0.287 & 1.278 & 0.813 & 2.010 & 0.527 & 1.172 & 0.716 & 1.917 \\
\hline & $70.0-79.9$ & 0.004 & 2.035 & 1.254 & 3.300 & 0.055 & 1.678 & 0.988 & 2.850 \\
\hline & $>80$ & 0.039 & 2.207 & 1.042 & 4.678 & 0.697 & 1.205 & 0.472 & 3.078 \\
\hline \multirow[t]{2}{*}{ Sex } & Female & & 1.000 & & & & 1.000 & & \\
\hline & Male & 0.122 & 0.770 & 0.553 & 1.072 & 0.038 & 0.646 & 0.428 & 0.975 \\
\hline \multirow[t]{2}{*}{ Alcohol anamnesis } & No & & 1.000 & & & & 1.000 & & \\
\hline & Yes & 0.807 & 0.958 & 0.682 & 1.347 & 0.412 & 1.200 & 0.776 & 1.857 \\
\hline \multirow[t]{2}{*}{ Smoking anamnesis } & No & & 1.000 & & & & 1.000 & & \\
\hline & Yes & 0.680 & 0.926 & 0.641 & 1.337 & 0.424 & 1.201 & 0.766 & 1.884 \\
\hline \multirow[t]{3}{*}{ Adjuvant therapy } & No & & 1.000 & & & & 1.000 & & \\
\hline & Radiotherapy & 0.551 & 0.891 & 0.608 & 1.304 & 0.306 & 0.807 & 0.535 & 1.217 \\
\hline & Radiochemotherapy & 0.181 & 0.744 & 0.481 & 1.148 & 0.055 & 0.611 & 0.369 & 1.011 \\
\hline \multirow[t]{2}{*}{ Extranodal spread } & No & & 1.000 & & & & 1.000 & & \\
\hline & Yes & 0.000 & 1.821 & 1.313 & 2.527 & 0.008 & 1.713 & 1.150 & 2.552 \\
\hline
\end{tabular}


distribution or a quartile cutoff was used for both univariate and multivariate survival analysis. Especially the median cutoff point of 0.055 in LNR is similar to the results being reported by different groups. Hereby, a LNR cutoff point of 0.06 was shown to significantly differentiate survival outcome in OSCC $[18,30]$.

Limitations of this study are mainly due to its retrospective character. Seven hundred nineteen patients met the inclusion criteria for this analysis. For further evaluation of the outcome within different LNRs, solely patients with histopathological verified lymph node metastasis qualified for our study. Of note, we performed one of the largest multicenter analyses regarding the role of LNR for predicting outcome in OSCC.

However, our analysis might be affected by concealed confounders, such as different treatment standards and surgical methods by the individual treating surgeon. Additionally, histopathological examination of dissected lymph nodes is crucial when it comes to obtaining a reliable basis to determine LNR. Hereby, examination of the surgical specimen was conducted by two experienced, board-certified pathologists. Furthermore, each patient undergoing surgery for OSCC is exclusively treated by a highly trained and experienced attending surgeon, so a comparable high-quality standard of surgical care can be assumed within the presented cohort.

Taken together, we were able to highlight LNR as a prognostic factor, determining outcome of patients with advanced stage OSCC.

\section{Conclusion}

In conclusion, our results indicate the importance of LNR as an independent prognostic parameter for OAS and RFS in OSCC patients with lymph node metastasis. Although the TNM classification already entails a lymph node staging system, the number of dissected lymph nodes and number of lymph node metastasis are currently not taken into account in this traditional staging system. However, we were able to clearly demonstrate that LNR is a valuable prognostic parameter in a population-based multicenter cohort study of OSCC patients in Eastern Bavaria. Incorporation of LNR as a prognostic marker in future staging systems might help to stratify patients' risk and in fact facilitates decision about the need of adjuvant treatment modalities.

Authors' contribution All authors contributed to the study conception and design. Material preparation, data collection, and analysis were performed by Steffen Spoerl, Michael Gerken, René Fischer, Stefanie Wolf, Felix Nieberle, Silvia Spoerl, and Gerrit Spanier. The first draft of the manuscript was written by Steffen Spoerl and Gerrit Spanier. All authors commented on previous versions of the manuscript or wrote passages for the first manuscript draft. All authors read and approved the final manuscript.
Funding information Open Access funding provided by Projekt DEAL.

\section{Compliance with ethical standards}

Conflict of interest The author declares that he has no conflict of interest.

Ethical approval The protocol was approved by the University of Regensburg Ethics Committee (GeschZ 191480 - 104), and it was conducted in accordance with the ethical standards of the declaration of Helsinki.

Informed consent Based on a retrospective analysis, a fully anonymized set of clinical data and in agreement with the decision of the Ethics Committee, signing an informed consent was not required.

Open Access This article is licensed under a Creative Commons Attribution 4.0 International License, which permits use, sharing, adaptation, distribution and reproduction in any medium or format, as long as you give appropriate credit to the original author(s) and the source, provide a link to the Creative Commons licence, and indicate if changes were made. The images or other third party material in this article are included in the article's Creative Commons licence, unless indicated otherwise in a credit line to the material. If material is not included in the article's Creative Commons licence and your intended use is not permitted by statutory regulation or exceeds the permitted use, you will need to obtain permission directly from the copyright holder. To view a copy of this licence, visit http://creativecommons.org/licenses/by/4.0/.

\section{References}

1. Shield KD, Ferlay J, Jemal A, Sankaranarayanan R, Chaturvedi AK, Bray F, Soerjomataram I (2017) The global incidence of lip, oral cavity, and pharyngeal cancers by subsite in 2012. CA Cancer J Clin 67:51-64. https://doi.org/10.3322/caac.21384

2. Gregoire V, Lefebvre JL, Licitra L, Felip E (2010) Squamous cell carcinoma of the head and neck: EHNS-ESMO-ESTRO clinical practice guidelines for diagnosis, treatment and follow-up. Ann Oncol 21(Suppl 5):v184-v186. https://doi.org/10.1093/annonc/ mdq185

3. Ding D, Stokes W, Eguchi M, Hararah M, Sumner W, Amini A, Goddard J, Somerset H, Bradley C, McDermott J, Raben D, Karam SD (2019) Association between lymph node ratio and recurrence and survival outcomes in patients with oral cavity cancer. JAMA Otolaryngol Head Neck Surg 145:53-61. https://doi.org/10.1001/ jamaoto.2018.2974

4. Panarese I, Aquino G, Ronchi A, Longo F, Montella M, Cozzolino I, Roccuzzo G, Colella G, Caraglia M, Franco R (2019) Oral and Oropharyngeal squamous cell carcinoma: prognostic and predictive parameters in the etiopathogenetic route. Expert Rev Anticancer Ther 19:105-119. https://doi.org/10.1080/14737140.2019. 1561288

5. Bernier J, Domenge C, Ozsahin M, Matuszewska K, Lefebvre JL, Greiner RH, Giralt J, Maingon P, Rolland F, Bolla M, Cognetti F, Bourhis J, Kirkpatrick A, van Glabbeke M (2004) Postoperative irradiation with or without concomitant chemotherapy for locally advanced head and neck cancer. N Engl J Med 350:1945-1952. https://doi.org/10.1056/NEJMoa032641

6. Cramer JD, Burtness B, Ferris RL (2019) Immunotherapy for head and neck cancer: recent advances and future directions. Oral Oncol 99:104460. https://doi.org/10.1016/j.oraloncology.2019.104460 
7. Burtness B, Harrington KJ, Greil R, Soulières D, Tahara M, de Castro G Jr, Psyrri A, Basté N, Neupane P, Bratland Å, Fuereder T, Hughes BGM, Mesía R, Ngamphaiboon N, Rordorf T, Wan Ishak WZ, Hong RL, González Mendoza R, Roy A, Zhang Y, Gumuscu B, Cheng JD, Jin F, Rischin D (2019) Pembrolizumab alone or with chemotherapy versus cetuximab with chemotherapy for recurrent or metastatic squamous cell carcinoma of the head and neck (KEYNOTE-048): a randomised, open-label, phase 3 study. Lancet 394:1915-1928. https://doi.org/10.1016/s0140-6736(19) 32591-7

8. Bertero L, Massa F, Metovic J, Zanetti R, Castellano I, Ricardi U, Papotti M, Cassoni P (2017) Eighth edition of the UICC classification of malignant tumours: an overview of the changes in the pathological TNM classification criteria — what has changed and why? Virchows Arch 472. https://doi.org/10.1007/s00428-017-2276-y

9. Brierley JD, Gospodarowicz MK, Wittekind C (eds) (2017) TNM classification of malignant tumours, eighth edn. Wiley, Chichester

10. Noguti J, De Moura CF, De Jesus GP, Da Silva VH, Hossaka TA, Oshima CT, Ribeiro DA (2012) Metastasis from oral cancer: an overview. Cancer Genomics Proteomics 9:329-335

11. Kreppel M, Nazarli P, Grandoch A, Safi AF, Zirk M, Nickenig HJ, Scheer M, Rothamel D, Hellmich M, Zoller JE (2016) Clinical and histopathological staging in oral squamous cell carcinoma - comparison of the prognostic significance. Oral Oncol 60:68-73. https://doi.org/10.1016/j.oraloncology.2016.07.004

12. Zirk M, Safi AF, Buller J, Nickenig HJ, Dreiseidler T, Zinser M, Drebber U, Zoller JE, Kreppel M (2018) Lymph node ratio as prognosticator in floor of mouth squamous cell carcinoma patients. $\mathrm{J}$ Craniomaxillofac Surg 46:195-200. https://doi.org/10.1016/j. jcms.2017.11.021

13. Subramaniam N, Balasubramanian D, Kumar N, Murthy S, Vijayan SN, Nambiar A, Vidhyadharan S, Thankappan K, Iyer S (2019) Lymph node staging systems in oral squamous cell carcinoma: a comparative analysis. Oral Oncol 97:92-98. https://doi.org/10. 1016/j.oraloncology.2019.08.002

14. Roberts TJ, Colevas AD, Hara W, Holsinger FC, Oakley-Girvan I, Divi V (2016) Number of positive nodes is superior to the lymph node ratio and American Joint Committee on Cancer N staging for the prognosis of surgically treated head and neck squamous cell carcinomas. Cancer 122:1388-1397. https://doi.org/10.1002/cncr. 29932

15. Zhu J, Xue Z, Zhang S, Guo X, Zhai L, Shang S, Zhang Y, Lu H (2018) Integrated analysis of the prognostic role of the lymph node ratio in node-positive gastric cancer: a meta-analysis. Int J Surg 57: 76-83. https://doi.org/10.1016/j.ijsu.2018.08.002

16. Ceelen W, Van Nieuwenhove Y, Pattyn P (2010) Prognostic value of the lymph node ratio in stage III colorectal cancer: a systematic review. Ann Surg Oncol 17:2847-2855. https://doi.org/10.1245/ s10434-010-1158-1

17. Elshaer M, Gravante G, Kosmin M, Riaz A, Al-Bahrani A (2017) A systematic review of the prognostic value of lymph node ratio, number of positive nodes and total nodes examined in pancreatic ductal adenocarcinoma. Ann R Coll Surg Engl 99:101-106. https:// doi.org/10.1308/rcsann.2016.0340

18. Gil Z, Carlson DL, Boyle JO, Kraus DH, Shah JP, Shaha AR, Singh B, Wong RJ, Patel SG (2009) Lymph node density is a significant predictor of outcome in patients with oral cancer. Cancer 115:57005710. https://doi.org/10.1002/cncr.24631
19. Suzuki H, Beppu S, Hanai N, Hirakawa H, Hasegawa Y (2016) Lymph node density predicts lung metastases in oral squamous cell carcinoma. Br J Oral Maxillofac Surg 54:213-218. https://doi.org/ 10.1016/j.bjoms.2015.11.002

20. Gospodarowicz MK, Sobin LH, Wittekind C (2010) TNM classification of malignant tumours. Wiley-Blackwell, Chichester

21. Charlson ME, Pompei P, Ales KL, MacKenzie CR (1987) A new method of classifying prognostic comorbidity in longitudinal studies: development and validation. J Chronic Dis 40:373-383

22. Shingaki S, Takada M, Sasai K, Bibi R, Kobayashi T, Nomura T, Saito C (2003) Impact of lymph node metastasis on the pattern of failure and survival in oral carcinomas. Am J Surg 185:278-284. https://doi.org/10.1016/s0002-9610(02)01378-8

23. Amin MB, Greene FL, Edge SB, Compton CC, Gershenwald JE, Brookland RK, Meyer L, Gress DM, Byrd DR, Winchester DP (2017) The eighth edition AJCC Cancer staging manual: continuing to build a bridge from a population-based to a more "personalized" approach to cancer staging. CA Cancer J Clin 67:93-99. https://doi. org/10.3322/caac. 21388

24. Zenga J, Divi V, Stadler M, Massey B, Campbell B, Shukla M, Awan M, Schultz CJ, Shreenivas A, Wong S, Jackson RS, Pipkorn P (2019) Lymph node yield, depth of invasion, and survival in node-negative oral cavity cancer. Oral Oncol 98:125-131. https://doi.org/10.1016/j.oraloncology.2019.09.028

25. Mamelle G, Pampurik J, Luboinski B, Lancar R, Lusinchi A, Bosq $\mathrm{J}$ (1994) Lymph node prognostic factors in head and neck squamous cell carcinomas. Am J Surg 168:494-498. https://doi.org/10.1016/ s0002-9610(05)80109-6

26. Rajappa SK, Maheshwari U, Jaipuria J, Singh AK, Goyal S, Batra U, Kumar R, Dewan AK (2019) Number of positive nodes - current relevance in determining prognosis of oral cavity cancer after the recent AJCC staging update. Oral Oncol 90:1-5. https://doi.org/10. 1016/j.oraloncology.2019.01.001

27. de Ridder M, Marres CC, Smeele LE, van den Brekel MW, Hauptmann M, Balm AJ, van Velthuysen ML (2016) A critical evaluation of lymph node ratio in head and neck cancer. Virchows Arch 469:635-641. https://doi.org/10.1007/s00428016-2015-9

28. Rudra S, Spiotto MT, Witt ME, Blair EA, Stenson K, Haraf DJ (2014) Lymph node density-prognostic value in head and neck cancer. Head Neck 36:266-272. https://doi.org/10.1002/hed.23299

29. Patel SG, Amit M, Yen TC, Liao CT, Chaturvedi P, Agarwal JP, Kowalski LP, Ebrahimi A, Clark JR, Cernea CR, Brandao SJ, Kreppel M, Zoller J, Fliss D, Fridman E, Bachar G, Shpitzer T, Bolzoni VA, Patel PR, Jonnalagadda S, Robbins KT, Shah JP, Gil Z (2013) Lymph node density in oral cavity cancer: results of the International Consortium for Outcomes Research. Br J Cancer 109: 2087-2095. https://doi.org/10.1038/bjc.2013.570

30. Ong W, Zhao R, Lui B, Tan W, Ebrahimi A, Clark JR, Soo KC, Tan NC, Tan HK, Iyer NG (2016) Prognostic significance of lymph node density in squamous cell carcinoma of the tongue. Head Neck 38(Suppl 1):E859-E866. https://doi.org/10.1002/hed.24113

Publisher's note Springer Nature remains neutral with regard to jurisdictional claims in published maps and institutional affiliations. 